\title{
A novel silk-like shell matrix gene is expressed in the mantle edge of the Pacific oyster prior to shell regeneration.
}

\section{$\operatorname{AUTHOR}(\mathrm{S}):$}

Takahashi, Jun; Takagi, Masaya; Okihana, Yumiko; Takeo, Kei; Ueda, Takahisa; Touhata, Ken; Maegawa, Shingo; Toyohara, Haruhiko

\section{CITATION:}

Takahashi, Jun ... [et al]. A novel silk-like shell matrix gene is expressed in the mantle edge of the Pacific oyster prior to shell regeneration.. Gene 2012, 499(1): 130-134

\section{ISSUE DATE:}

2012-05-10

\section{URL:}

http://hdl.handle.net/2433/155565

\section{RIGHT:}

(c) 2011 Elsevier B.V.; この論文は出版社版でありません。引用の際には 出版社版をご確認ご利用ください。; This is not the published version. Please cite only the published version. 
1 A novel silk-like shell matrix gene is expressed in the mantle edge of the Pacific oyster

2 prior to shell regeneration

3

4 Jun Takahashi ${ }^{\text {a,b }}$, Masaya Takagi ${ }^{\text {a }}$, Yumiko Okihana ${ }^{a}$, Kei Takeo ${ }^{\text {a }}$, Takahisa Ueda ${ }^{\text {a }}$,

$5 \quad$ Ken Touhata $^{\mathrm{c}}$, Shingo Maegawa ${ }^{\mathrm{d}}$, Haruhiko Toyohara ${ }^{\mathrm{a}, *}$

6

7 a: Graduate School of Agriculture, Kyoto University, Kyoto 606-8502, Japan

8 b: Research Fellow of the Japan Society for the Promotion of Science (JSPS), Tokyo

9 102-8472, Japan

10 c: Biochemistry and Food Technology Division, Fisheries Research Agency of Japan,

11 Kanagawa 236-8648, Japan

12 d: Graduate School of Informatics, Department of Intelligence Science and Technology,

13 Kyoto University, Kyoto 606-8501, Japan

$14 *$ : Corresponding author

> E-mail: $\quad$ toyohara@ $\quad$ kais.kyoto-u.ac.jp

$16>$ Tel / Fax:

$+81-75-753-6446$

$>$ Present address:

Graduate School of Agriculture, Kyoto University,

21 Keywords:

22 Biomineralization; Calcite; Pacific oyster; Poly-alanine; Spider-silk protein 


\section{Abstract}

2

During shell formation, little is known about the functions of organic matrices, especially about the biomineralization of shell prismatic layer. We identified a novel gene, shelk2, from the Pacific oyster presumed to be involved in the shell biosynthesis. The Pacific oyster has multiple copies of shelk2. Shelk2 mRNA is specifically expressed on the mantle edge and is induced during shell regeneration, thereby suggesting that Shelk 2 is involved in shell biosynthesis. To our surprise, the database search revealed that it encodes a spider silk-like alanine-rich protein. Interestingly, most of the Shelk2 primary structure is composed of two kinds of poly-alanine motifs $-\mathrm{GXNA}_{\mathrm{n}}(\mathrm{S})$ and $\mathrm{GSA}_{\mathrm{n}}(\mathrm{S})$ - where $\mathrm{X}$ denotes Gln, Arg or no amino acid. Occurrence of common motifs of Shelk2 and spider silk led us to the assumption that shell and silk are constructed under similar strategies despite of their living environments. 


\section{Introduction}

Molluscan shells are known to be made of $\mathrm{CaCO}_{3}$ crystals, and their shapes differ according to species. However, the mechanism by which these shells are synthesized is yet unclear. They are among the most extensively studied biominerals and are composed of various types of layers, including periostracum, foliate, cross-lamellar, prismatic, and nacreous (Mann, 2001; Wilt et al., 2003; Marin et al., 2008). Organic matrices such as polysaccharides and proteins can affect the diversity of shell shapes by arranging the $\mathrm{CaCO}_{3}$ crystals in a specific manner. Some proteins such as Aspein (Tsukamoto et al., 2004), Asprich (Gotliv et al., 2005), Caspartin, Calprismin (Marin et al., 2005), KRMP (Zhang et al., 2006), MSI31 (Sudo et al., 1997), and Prismarin-14 (Suzuki et al., 2004; Suzuki and Nagasawa, 2007) are reported to be involved in the synthesis of the prismatic layer, which is composed of calcite crystalline structures. Most of the organic matrix proteins identified thus far are associated with the synthesis of prismatic layers in the Japanese pearl oyster Pinctada fucata. These proteins have been mainly isolated by decalcification of shells using calcium chelators or acids. Further, some soluble as well as insoluble proteins harboring critical protein-binding domains have been extracted for the analysis of shell biomineralization. However, because this conventional method is better suited for identification of abundant proteins, certain vital proteins could not be isolated because of their low solubility and/or instability in the solutions used for the extraction.

To identify other essential proteins involved in shell biosynthesis, we focused on the mantle instead of the shell. Miyamoto et al. (1996) showed that the mantle edge is known to synthesize the calcite of the prismatic layer. We cloned certain mantle edge-specific genes from the Pacific oyster Crassostrea gigas by using a subtractive hybridization method. We succeeded in identifying two novel genes specifically expressed on the mantle edge. Unexpectedly, the deduced amino acid sequences of both the resulting proteins were found to 
1 be highly homologous to those of spider silk proteins. Thus, we termed these oyster genes

2 "shelk," meaning silk-in-the-shell, and designated these proteins as Shelk1 and Shelk2. Our

3 attempts to characterize both these genes have shown that they are indeed expressed in the

4 mantle edge.

6 2. Materials and Methods

$7 \quad$ 2.1. Materials

All procedures were performed according to published molecular cloning protocols or according to the manufacturers' instructions. The Advantage 2 PCR Enzyme System (Clontech) or TaKaRa Ex Taq (TAKARA) was used for polymerase chain reactions (PCRs). PCR primers were commercially synthesized (Hokkaido System Science). In a thermal cycler T-Gradient Thermoblock (Biometra), the standard PCR reactions were performed under the following conditions: $94{ }^{\circ} \mathrm{C}$ for $3 \mathrm{~min}$; $30-40$ cycles of $98{ }^{\circ} \mathrm{C}$ for $30 \mathrm{~s}, 55-60{ }^{\circ} \mathrm{C}$ for $30 \mathrm{~s}$, and $72{ }^{\circ} \mathrm{C}$ for $60-75 \mathrm{~s}$. PCR products were cloned into the pGEM-T Easy vector (Promega) before sequencing (Fasmac). All restriction enzymes (TOYOBO) were used under the recommended buffer conditions. Commercially available adult Pacific oysters and the Iwagaki oyster Crassostrea nippona were maintained in artificial seawater without feed for 1 week before using them for the experiments. Meretrix lusoria (clam), Mizuhopecten yessoensis (Japanese scallop), Mytilus galloprovincialis (mussel), Hemicentrotus pulcherrimus (sea urchin), and Halichondria japonica (sponge) were collected from the sea around Japan.

\subsection{Subtractive cloning of shelk2 cDNA}

The mantle edge and mantle pallial were collected from a Pacific oyster. The mRNA was extracted using the MicroPoly(A)Purist Kit (Ambion). Briefly, suppression 
subtractive hybridization was performed between the mantle edge and mantle pallial by using the PCR-Select cDNA Subtraction kit (Clontech). We identified several genes specifically expressed in the mantle edge (unpublished data). Full-length shelk2 cDNA was cloned by 5' and 3' RACE-PCR using the SMART RACE cDNA Amplification Kit (Clontech). PCR reactions were performed under the standard PCR program using the primers provided in the kit and the gene-specific primers for 5' and 3' RACE-PCRs (5'-CTA ATG GTC CAT ACG GTT TGT GAT AAT AG-3', 5'-CGT CAT ACT TGG AAT AGT GAC TAT AAG TG-3', 5'-GAT CAC CCG ACC AAG TCC AGT GAC AC-3', and 3'-GTT CTA TAA AAA CCA AGC AAA AGA CGA C-5').

\subsection{Genome walking of the shelk2 gene}

Genomic DNA of the Pacific oyster and other marine organisms was isolated from fresh tissues (Asahida et al., 1996). Primers for genomic DNA cloning were designed on the basis of the Pacific oyster shelk2 cDNA sequence (5'-ATG CTG AAG CTT GTC TCC ATC GTT TGC CTT-3' and 5'-TTA ATA GGT CTT TTT ATG TCT GAT GCC ACC-3'), with the standard PCR program. The GenomeWalker Universal Kit (Clontech) was used to obtain the shelk2 gene using $250 \mathrm{ng}$ of genomic DNA as a template.

\subsection{Observation of shell regeneration and in situ hybridization}

The Pacific oyster shells were cut on the ventral side (the opposite side of the umbo) into approximately $30-\mathrm{mm}$ wide and $10-\mathrm{mm}$ thick pieces by using a pair of nippers and used for time-dependent observations and in situ hybridization experiments during the shell biosynthesis process.

Non-radioactive in situ hybridization was performed using paraffin sections from the mantle of Pacific oysters (Sakamoto et al., 2008). Digoxigenin UTP-labeled antisense and 
sense RNA probes were transcribed from shelk2 partial cDNA (349 bp) by using a DIG RNA labeling mix (Roche Diagnostics) under the standard PCR program. The mantles of the Pacific oysters were fixed in Bouin's fixative. Fixed tissues were dehydrated in an ethanol series and embedded in paraffin wax. Thin sections of approximately $8-\mu \mathrm{m}$ thickness were prepared using a microtome PR-50 (Yamato Koki).

\subsection{Tissue-specific RT-PCR of shelk2}

Total RNA was extracted from liquid nitrogen frozen adult Pacific oyster tissues—mantle edge, mantle pallial, gill, intestine, and adductor muscle—by using Sepasol-RNA I (Nacalai Tesque). The RNA was purified using RNase-Free DNase (Promega) and Oligotex-dT30<super> (TAKARA). ReverTra Ace (TOYOBO) was used for reverse transcription and cDNA construction. PCR was performed with gene-specific primers (5'-TTG GAG GAC TCG TCG GTC TGG GTG GTG-3' and 5'-GAA TCC ACT TGC AGA TGC AGC AGC AGC G-3') with the standard PCR program, based on the reverse-transcribed cDNA template.

\subsection{Southern blotting of the shelk2 gene}

Digoxigenin UTP-labeled DNA probes were designed from shelk2 partial cDNA (231 bp) by standard PCR using alkali-labile DIG-11-dUTP (Roche) and primers (5'-GTC ATT GGA GGA CTC GTC GG-3' and 5'-TGG GAC TGA TCC GAA TCC AC-3'). The Pacific oyster genomic DNA was partially digested using the restriction enzymes BamHI, EcoRI, and HindIII, and used for hybridization. DNA transfer, fixation to the membrane (Biodyne Plus $0.45 \mu \mathrm{m}$ (PALL)), and hybridization were performed with the DIG High Prime DNA Labeling and Detection Starter Kit I (Roche). CDP-star (GE Healthcare UK), Hi-RENDOL (FUJIFILM), and Hi-RENFIX (FUJIFILM) were used for immunological 
1

2

3

4

5

6

7

detection.

\section{Results}

\subsection{Identification of shelk2}

First, we partially excised the edge of the prismatic layer of the oyster shell to observe shell regeneration (Fig. 1). After $24 \mathrm{~h}$, the mantle edge appeared at the dissected area of the shell for regeneration and began to construct a film-like shell framework structure, which is considered a part of the new shell. This fresh shell framework structure grew with time, and had covered the broken area within 5 days of cutting.

In the present study, we report the structure of Shelk2, while we are currently pursuing the structural analysis of Shelk1. The full-length cDNA sequence of shelk2 (GenBank ID: AB474183) was obtained from mRNA specifically expressed at the mantle edge of the Pacific oyster. We obtained an 894-bp fragment with a coding sequence (CDS) corresponding to 297 amino acids of the deduced protein sequence (Fig. 2). From the results of 5' and 3' RACE-PCR and genome walking, the CDS of shelk2 was mapped into a single exon (exon 2). A sequence of 16 amino acids at the $\mathrm{N}$-terminus is thought to represent a putative signal peptide on the basis of the results obtained using the SignalP 4.0 (http://www.cbs.dtu.dk/services/SignalP/). The deduced amino acid sequence has 12 poly-alanine (poly-Ala) repeat motifs, 3 repeats of which are accompanied by PYYGFNLGG (Fig. 3a). Each poly-Ala motif has a series of 6-10 Ala residues, and sometimes, a Ser at the C-terminus or middle of the motif. These poly-Ala motifs do not exist as a single motif in Shelk2.

The results of Protein BLAST (blastp) homology searches of Shelk2 against the protein databases of NCBI (http://www.ncbi.nlm.nih.gov/) and Compagen (http://compagen.zoologie.uni-kiel.de/) revealed no existing or putative homologs under 
1 default searching conditions at the expect threshold $(\mathrm{E} \leq 10)$. However, typical poly-Ala

2 motifs have been reported in the silk proteins of spiders and some insects. For example, a

3 spider dragline silk fibroin, Spidroin 2 of Nephila clavipes (GenBank ID: M92913), has

4 almost the same length of a series of poly-Ala motifs (Fig. 3b).

5

$6 \quad 3.2$. shelk2 expression is coupled with shell regeneration in the mantle edge. To elucidate whether shelk 2 is involved in shell biosynthesis, we examined mantle tissue by in situ hybridization for the expression of shelk 2 mRNA during shell biosynthesis. As a result, we determined that shelk2 mRNA was specifically expressed in the outer fold of the mantle edge (Fig. 4), an area known to express genes involved in the biosynthesis of the prismatic layer of the shell (Miyamoto et al., 1996). Furthermore, the expression of shelk2 mRNA gradually increased during the shell biosynthesis process, before the shell framework structure covered the dissected shell area (Figs. 1 and 4). mRNA expression level at $12 \mathrm{~h}$ was higher than those at $0 \mathrm{~h}$, and further increased until $72 \mathrm{~h}$. Taken together, we assume that Shelk2 is involved in the biosynthesis of prismatic layers in the oyster shells.

\subsection{Structural analysis of the shelk2 gene}

To verify the presence of shelk2 in the oyster genome, we performed Southern blotting and genome walking. At least 8 bands were obtained in the genomic Southern blotting (Fig. 5), thereby suggesting the presence of multiple gene structures of shelk2. As a result of genome waling, we actually cloned 7 other distinct shelk2-like genes with 1-12 base nucleotide displacement (GenBank ID: AB526832-AB526838).

\subsection{Homologous gene searching of shelk2}

To verify the distribution of shelk2 among marine organisms, we performed PCR 
analysis on the following marine organisms containing biominerals: Iwagaki oyster (a species related to the Pacific oyster), clam, Japanese scallop, sea urchin, and sponge. As a result, we obtained a 987-bp fragment encoding the CDS from Iwagaki oyster corresponding to 328 amino acids of deduced protein sequence (GenBank ID: AB474184). Because of high amino acid sequence identity $(67.4 \%)$ with the Pacific oyster Shelk2, and conservation of the poly-Ala motifs and 3 repeats of the characteristic PYYGFNLGG motif, it is strongly suggested that the cloned gene from Iwagaki oyster is an ortholog of shelk2 from the Pacific oyster (Fig. 3a). However, we have failed to clone any additional orthologs from sea urchin, sponge, or other bivalves.

\section{Discussion}

We identified a novel gene that encodes a spider silk-like protein termed Shelk2 that harbors 2 unique types of poly-Ala repeat motifs: a $\mathrm{GSA}_{n}(\mathrm{~S})$ and $\mathrm{GXNA}_{n}(\mathrm{~S})$ motifs, where $\mathrm{X}$ indicates Gln, Arg, or no amino acid. Each type consists of a series of 6-10 Ala residues, some of which are interspersed with Thr and/or Ser residues. In addition, we identified 3 repeats of the novel motif PYYGFNLGG, followed by the $\mathrm{GSA}_{n}(\mathrm{~S})$ type poly-Ala motif in Shelk2. Importantly, both poly-Ala motifs do not exist as a single motif in Shelk2 (Fig. 3a). The GSAn(S) type motif was identified in various spider dragline silk proteins such as Spidroin 2 of N. clavipes (GenBank ID: M92913) (Hinman and Lewis, 1992), and fibroin-4 of Araneus diadematus (GenBank ID: U47856) (Guerette et al., 1996). It was also found in the molluscan protein MSI60 of the pearl oyster P. fucata (GenBank ID: D86074) (Sudo et al., 1997). Thus, Shelk2 and MSI60 could be classified as poly-Ala sequence-containing proteins, although they differ in the following 3 characteristics: (i) The molecular weight of MSI60 is $60 \mathrm{kDa}$, while that of Shelk2 is $25.6 \mathrm{kDa}$; (ii) MSI60 has Asp-rich regions that may enable $\mathrm{Ca}^{2+}$ binding, whereas Shelk2 lacks regions rich in anionic 
amino acids; and (iii) Shelk2 has unique PYYGPLNGG motifs, whereas MSI60 does not. These findings suggest that Shelk2 and MSI60 share similar but distinct functions in the process of shell biosynthesis. The results of RT-PCR (data not shown) and in situ hybridization (Fig. 4) revealed that both Shelk2 and MSI60 mRNAs are specifically expressed on the mantle edge (Sudo et al., 1997), which is involved in the formation of prismatic layers in molluscan shells (Miyamoto et al., 1996).

However, although 4 repeats of $\mathrm{GSA}_{n}(\mathrm{~S})$ were identified in $\mathrm{MSI}_{60}$, the $\mathrm{GXNA}_{n}(\mathrm{~S})$ type poly-Ala motif of Shelk2 has not been identified in any expressed animal protein. Unlike the poly-Ala motifs in spider silk proteins, the $\mathrm{GXNA}_{n}(\mathrm{~S})$-type poly-Ala motifs in Shelk2 often contains Gln at the $\mathrm{X}$ position, which may enable $\mathrm{Ca}^{2+}$ binding for shell formation. The interaction between $\mathrm{Ca}^{2+}$ and Gln and/or Asn was suggested on the basis of a study that calculated the predictive potential energy of protein binding (Dudev et al., 2003). The poly-Ala motifs preceded by Gln and/or Asn are thought to function not only as a framework unit, but also as elements promoting $\mathrm{Ca}^{2+}$ capture for the effective formation of $\mathrm{CaCO}_{3}$ crystals in the shell.

It is conceivable that Shelk2 of Iwagaki oysters also has the same two types of poly-Ala motifs. Interestingly, Iwagaki oyster Shelk2 has 14 poly-Ala motifs, whereas the Pacific oyster has 12 (Fig. 3a). This may be because of the difference in gene duplication of poly-Ala motifs between both the oyster species after evolutionary divergence. We have failed to detect shelk2 homologous genes in clam, Japanese scallop, sea urchin, and sponge, most likely due to mismatching of PCR primers.

In contrast, we have found that the purple sea urchin Strongylocentrotus purpuratus has some putative proteins that have poly-Ala motifs, as determined from the NCBI BLAST database (invertebrates/echinoderms). However, we could not identify poly-Ala motifs that included GQN or GRN. In addition, we also have found that a coral species, Acropora 
1 digitifera, for which the whole genome has been sequenced (Shinzato et al., 2011), has

2 putative proteins harboring $\mathrm{GQN}(\mathrm{A})_{3}, \mathrm{GRN}(\mathrm{A})_{3}, \mathrm{GS}(\mathrm{A})_{4}$, and $(\mathrm{A})_{5} \mathrm{SG}$. This suggests that

3 poly-Ala containing proteins may be involved in the process of $\mathrm{CaCO}_{3}$ biomineralization in

4 marine organisms, including shells, sea urchins, and corals. Further studies on the whole

5 genome structure of biomineral-making animals will facilitate the elucidation of the

6 distribution and role of poly-Ala motifs in biomineralization.

7

\section{Acknowledgements}

This work was financially supported by a Grant-in-Aid for JSPS Fellows, and

Scientific Research (B) (Grant no. 18380124) from the Japan Society for the Promotion of Science (JSPS) and also supported by the Sekisui Chemical Grant Program for Research on Manufacturing Based on Learning from Nature for the fiscal year 2005.

\section{References}

Asahida, T., Kobayashi, T., Saitoh, K., Nakayama, I., 1996. Tissue preservation and total DNA extraction from fish stored at ambient temperature using buffers containing high concentration of urea. Fish. Sci. 62, 727-730.

Dudev, T., Lin, Y., Dudev, M., Lim, C., 2003. First-second shell interactions in metal binding sites in proteins: a PDB survey and DFT/CDM calculations. J. Am. Chem. Soc. 125, $3168-3180$.

Gotliv, B.A., Kessler, N., Sumerel, J.L., Morse, D.E., Tuross, N. Addadi, L., Weiner, S., 2005. Asprich; a novel aspartic acid-rich protein family from the prismatic shell matrix of the bivalve Atrina rigida. ChemBioChem 6, 304-314.

Guerette, P.A., Ginzinger, D.G., Weber, B.H.F., Gosline, J.M., 1996. Silk properties determined by gland-specific expression of a spider fibroin gene family. Science 272, 
1

$112-115$.

Hinman, M.B., Lewis, R.V., 1992. Isolation of a clone encoding a second dragline silk fibroin, J. Biol. Chem. 267, 19320-19324.

Mann, S., 2001. Biomineralization: Principles and Concepts in Bioinorganic Materials Chemistry, Oxford University Press, New York.

Marin, F., Amons, R., Guichard, N., Stigter, M., Hecker, A., Luquet, G., Layrolle, P., Alcaraz, G., Riondet, C., Westbroek, P., 2005. Caspartin and calprismin, two new proteins of the shell calcitic prisms of the Mediterranean fan mussel Pinna nobilis. J. Biol. Chem. 280, 33895-33908.

Marin, F., Luquet, G., Marie, B., Medakovic, D., 2008. Molluscan shell proteins: primary structure, origin, and evolution. Curr. Top. Dev. Biol. 80, 209-276.

Miyamoto, H., Miyashita, T., Okushima, M., Nakano, S., Morita, T., Matsushiro, A., 1996. A carbonic anhydrase from the nacreous layer in oyster pearls. Proc. Natl. Acad. Sci. USA 93, 9657-9660.

Sakamoto, K., Uji, S., Kurokawa, T., Toyohara, H., 2008. Immunohistochemical, in situ hybridization and biochemical studies on endogenous cellulase of Corbicula japonica. Comp. Biochem. Physiol. B. Biochem. Mol. Biol. 150, 216-221.

Shinzato, C., Shoguchi, E., Kawashima, T., Hamada, M., Hisata, K., Tanaka, M., Fujie, M., Fujiwara, M., Koyanagi, R., Ikuta, T., Fujiyama, A., Miller, D.J., Satoh, N., 2011. Using the Acropora digitifera genome to understand coral responses to environmental change, Nature 476, 320-323.

Sudo, S., Fujikawa, T., Nagakura, T., Ohkubo, T., Sakaguchi, K., Tanaka, M., Nakashima, K., Takahashi, T., 1997. Structures of mollusc shell framework proteins. Nature 387, 563-564.

Suzuki, M., Murayama, E., Inoue, H., Ozaki, N., Tohse, H., Kogure, T., Nagasawa, H., 2004. 
1

2

Characterization of prismalin-14, a novel matrix protein from the prismatic layer of the Japanese pearl oyster (Pinctada fucata). Biochem. J. 382, 205-213.

Suzuki, M., Nagasawa, H., 2007. The structure-function relationship analysis of Prismalin-14 from the prismatic layer of the Japanese pearl oyster, Pinctada fucata, FEBS J., 274, $5158-5166$.

Tsukamoto, D., Sarashina, I., Endo, K., 2004. Structure and expression of an unusually acidic matrix protein of pearl oyster shells. Biochem. Biophys. Res. Commun. 320, $1175-1180$.

Wilt, F.H., Killian, C.E., Livingston, B.T., 2003. Development of calcareous skeletal elements in invertebrates. Differentiation 71, 237-250.

Zhang, C., Xie, L., Huang, J., Liu, X., Zhang, R., 2006. A novel matrix protein family participating in the prismatic layer framework formation of pearl oyster, Pinctada fucata. Biochem. Biophys. Res. Commun. 344, 735-740. 


\section{$1 \quad$ Figure captions}

2 Fig. 1. Time course of shell regeneration process beginning with the shell cut. The bar

3 indicates $1 \mathrm{~mm}$. The mantle edge of the oyster appears at the edge of cut shell after $12 \mathrm{~h}$.

4 The newly fresh shell framework (arrow heads) formed by the mantle edge can be observed

$5 \quad$ after $24 \mathrm{~h}$, and gradually increased up to 5 days.

6

7 Fig. 2. The cDNA sequence of shelk2 (GenBank ID: AB474183) and deduced amino acid sequence of Shelk2 protein. The putative signal peptide is indicated in italics. The stop codon is indicated with an asterisk. The nucleotides used for in situ hybridization are shaded. Arrows indicate the binding sites of the primers used for genomic Southern blotting.

Fig. 3. (a) Schematic representation of the Shelk 2 protein of the Pacific oyster and Iwagaki oyster. A sequence of 16 amino acids at the $\mathrm{N}$-terminal is thought to represent a putative signal peptide. The diamonds indicate poly-Ala motifs consisting of $\operatorname{GSA}_{n}(S)$ or $\operatorname{GXNA}_{n}(S)$ sequences, where $\mathrm{X}$ denotes Gln, Arg or no amino acid. The ellipses represent the 3 repeats of PYYGFNLGG motif followed by the $\mathrm{GSA}_{n}(\mathrm{~S})$ type poly-Ala motifs. (b) The alignment of Shelk2 and a spider dragline silk protein Spidron2 of N. clavipes (GenBank ID: M92913).

Fig. 4. (a) The overhead view of adductor muscle (AM), gill (Gi), gonad (Go), mantle edge (ME) and mantle pallial (MP) of the Pacific oyster with shell.

(b) The cross-section diagram of the Pacific oyster mantle and shell layers. The heavy line in the outer fold (OF) of the mantle edge indicates the expression area of shelk2 mRNA. (c) In situ hybridization during shell biosynthesis reveals the shelk2 mRNA expressed in OF, represented by stained cellular areas (arrow heads). The mRNA expression levels gradually increased up to $72 \mathrm{~h}$ of 
1 biosynthesis. The bar indicates $200 \mu \mathrm{m}$. The negative control section stained with the

2 sense probe showed no signals (data not shown).

3

4 Fig. 5. Southern blotting of shelk2 genomic DNA digested with the restriction enzymes;

5 BamHI (lane 1), EcoRI (lane 2), and HindIII (lane 3) shows the oyster has multiple

$6 \quad$ shlek2-like genes in its genome. $1 \%$ agarose gel was used for the analysis. 
Fig. 1.

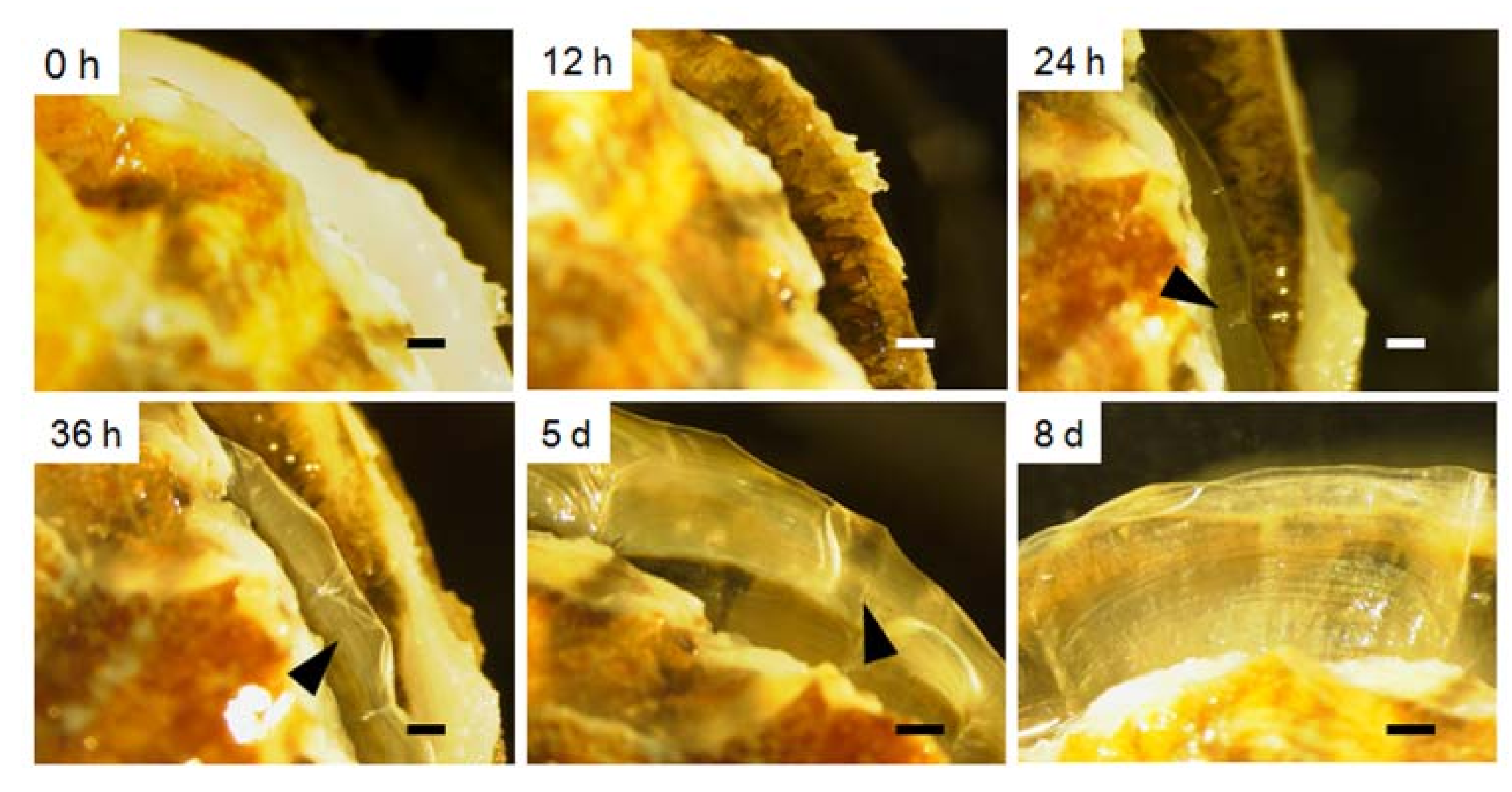


61 TCC ATC GTt TGC CTT TTt GCC TGT ACA TTC GCA GGT GAT tAT AAC ACT TAT AGT CAC TAT $\begin{array}{llllllllllllllllllllll}S & I & \boldsymbol{V} & \boldsymbol{C} & \boldsymbol{L} & \boldsymbol{F} & \boldsymbol{A} & \boldsymbol{C} & \boldsymbol{T} & \boldsymbol{F} & \boldsymbol{A} & \mathrm{G} & \mathrm{D} & \mathrm{Y} & \mathrm{N} & \mathrm{T} & \mathrm{Y} & \mathrm{S} & \mathrm{H} & \mathrm{Y}\end{array}$

121 TCC AAG TAT GAC GAC TAT TAT CAC AAA CCG TAT GGA CCA TTA GGT GGA GTC GGT GGA GTA $\begin{array}{llllllllllllllllllllllll}\mathrm{S} & \mathrm{K} & \mathrm{Y} & \mathrm{D} & \mathrm{D} & \mathrm{Y} & \mathrm{Y} & \mathrm{H} & \mathrm{K} & \mathrm{P} & \mathrm{Y} & \mathrm{G} & \mathrm{P} & \mathrm{L} & \mathrm{G} & \mathrm{G} & \mathrm{V} & \mathrm{G} & \mathrm{G} & \mathrm{V}\end{array}$

181 GGC TCA GGA ATT GTT GGC TCT GGT GGT GTC ATT GGA GGA CTC GTC GGT CTG GGT GGT GGA

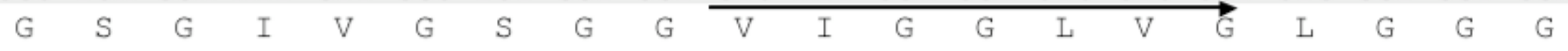

241 TCT GCA ACT GCT AGT GCC GCC GCT GCA GGA AAT AGC GCA GCA GCA GCT GCT GCT GCT GCA $\begin{array}{llllllllllllllllllll}\mathrm{S} & \mathrm{A} & \mathrm{T} & \mathrm{A} & \mathrm{S} & \mathrm{A} & \mathrm{A} & \mathrm{A} & \mathrm{A} & \mathrm{G} & \mathrm{N} & \mathrm{S} & \mathrm{A} & \mathrm{A} & \mathrm{A} & \mathrm{A} & \mathrm{A} & \mathrm{A} & \mathrm{A} & \mathrm{A}\end{array}$

301 GCT GGT CGA AAT GCT GCC GCC GCT GCT GCA GCT GCT GTA GGA CAA AAT GCT GCC GCC GCC $\begin{array}{llllllllllllllllllllll}\text { A } & G & R & N & A & A & A & A & A & A & A & A & V & G & Q & N & A & A & A & A\end{array}$

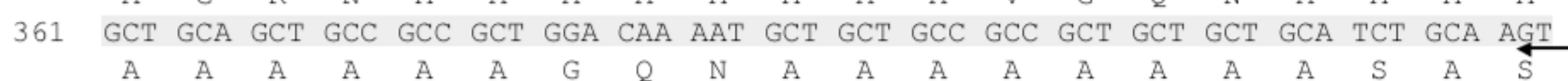
421 GGA TTC GGA TCA GTC CCA ACC TTT CCA TAC TAT GGT ACT CCC TAC TAT GGA TTC AAT TTA

$\begin{array}{ccccccccccccccccccccccccc} & \text { G } & \text { F } & \text { G } & \text { S } & \text { V } & \text { P } & \text { T } & \text { F } & \text { P } & Y & Y & \text { G } & \text { T } & \text { P } & Y & Y & \text { G } & \text { F } & N & \text { L } \\ 481 & \text { GGA } & \text { GGA } & \text { GGA } & \text { TCA } & \text { GCT } & \text { GCT } & \text { GCC } & \text { GCC } & \text { GCT } & \text { GCT } & \text { GCT } & \text { GCA } & \text { AGC } & \text { AGT } & \text { GGC } & \text { TCA } & \text { GCT } & \text { GCC } & \text { GCC } & \text { GCT }\end{array}$ $\begin{array}{llllllllllllllllllll}G & G & G & S & A & A & A & A & A & A & A & A & S & S & G & S & A & A & A & A\end{array}$

541 GCC GCC GCC GCT GCA TCT GCC AGC GGA CTT GGA TCA TTC CCA ACG TTT CCA TAC TAT GGT $\begin{array}{lllllllllllllllllllllllllll}A & A & A & A & A & S & A & S & G & L & G & S & F & P & T & F & P & Y & Y & G\end{array}$

601 GTC CCC TAC TAT GGA TTC AAT CTG GGA GGA GGA TCA GCT GCT GCT GCC GCC GCT GCT GCC $\begin{array}{llllllllllllllllllllllll}\mathrm{V} & \mathrm{P} & \mathrm{Y} & \mathrm{Y} & \mathrm{G} & \mathrm{F} & \mathrm{N} & \mathrm{L} & \mathrm{G} & \mathrm{G} & \mathrm{G} & \mathrm{S} & \mathrm{A} & \mathrm{A} & \mathrm{A} & \mathrm{A} & \mathrm{A} & \mathrm{A} & \mathrm{A} & \mathrm{A}\end{array}$

661 AGT GGT GGT TCT GCT GCT GCC GCT GCT GCT GCA TCT GCC AGT AGA TTT GCA TCA TTC CCC

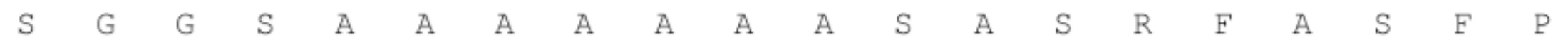

721 TAT TAT TAT GGA AAC CAA GTT AGC TTT CCT TAC TAT GgA TTC AAT CTA GGA GGT GGA TCG $\begin{array}{lllllllllllllllllllllll}Y & Y & Y & G & N & Q & V & S & F & P & Y & Y & G & F & N & L & G & G & G & S\end{array}$

781 GCT GCT GCA GCC GCC GCT GCC GCT GCT GGA CAA AAT GCT GCC GCT GCC GCC GCC GCC GCC $\begin{array}{llllllllllllllllllll}\mathrm{A} & \mathrm{A} & \mathrm{A} & \mathrm{A} & \mathrm{A} & \mathrm{A} & \mathrm{A} & \mathrm{A} & \mathrm{A} & \mathrm{G} & \mathrm{Q} & \mathrm{N} & \mathrm{A} & \mathrm{A} & \mathrm{A} & \mathrm{A} & \mathrm{A} & \mathrm{A} & \mathrm{A} & \mathrm{A}\end{array}$

841 GCT GGA CAA AAC GCC GCT GCT GCC TCC GCT GCT GCT GCA TCC GGA AGT ATA TTC AAC GGA $\begin{array}{llllllllllllllllllllllllll}A & G & Q & N & A & A & A & A & S & A & A & A & A & S & G & S & I & F & N & G\end{array}$

901 CCT ATt TTT GgT GgC ATC AGA CAT AAA AAg ACC TAT TAA AgA AAA GTG ACG TCG TCT TTT $\begin{array}{llllllllllllllll}P & I & F & G & G & I & R & H & K & K & T & Y\end{array}$

961 GCT TGG TTT TTA TAG AAC TTA TAA AAA ATA AAA CTG ATT AAT GCT AAA AAA AAA AAA AAA 1021 AAA AAA AAA AAA 
Fig. 3.

a) Pacific oyster (C. gigas)

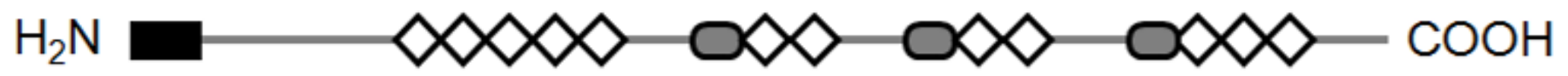

Iwagaki oyster (C. nippona)

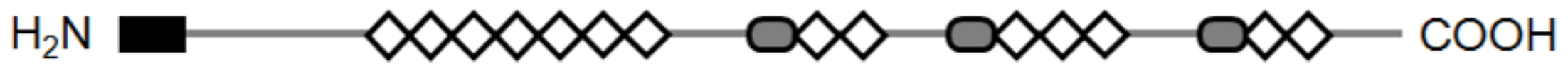

- Signal peptide $\diamond$ Poly-alanine $\oslash$ PYYGFNLGG

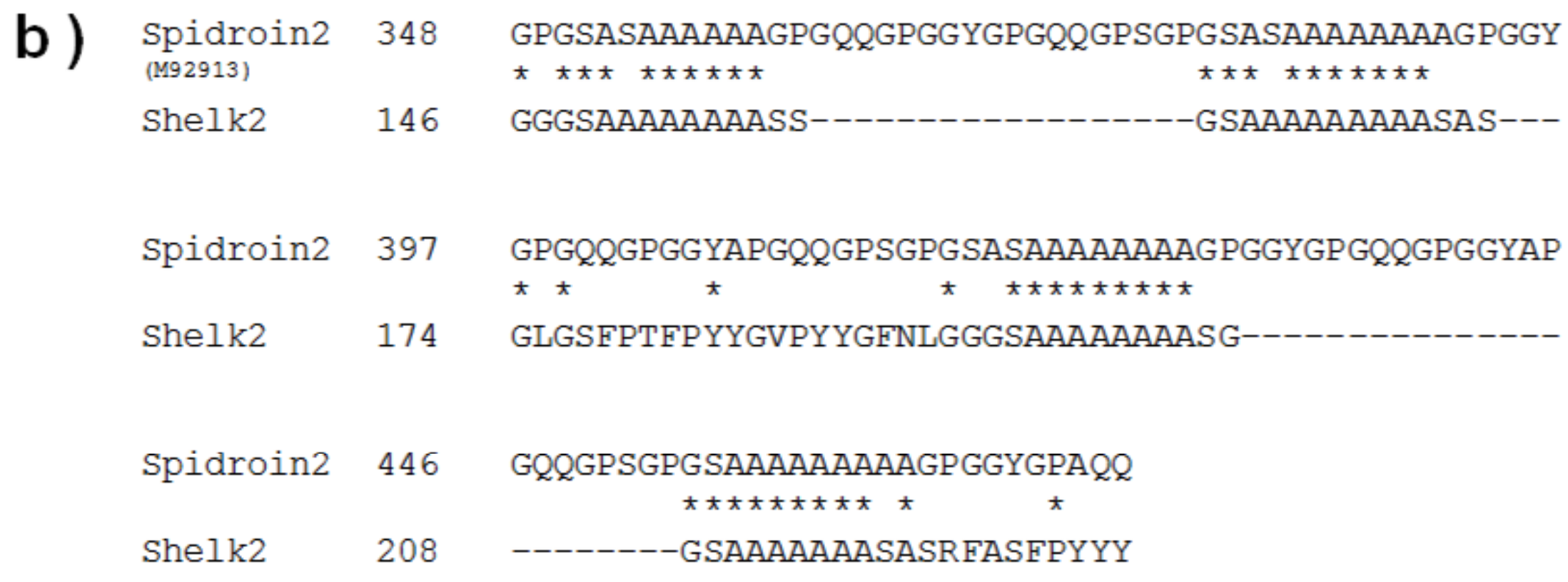


Fig. 4.

(a)

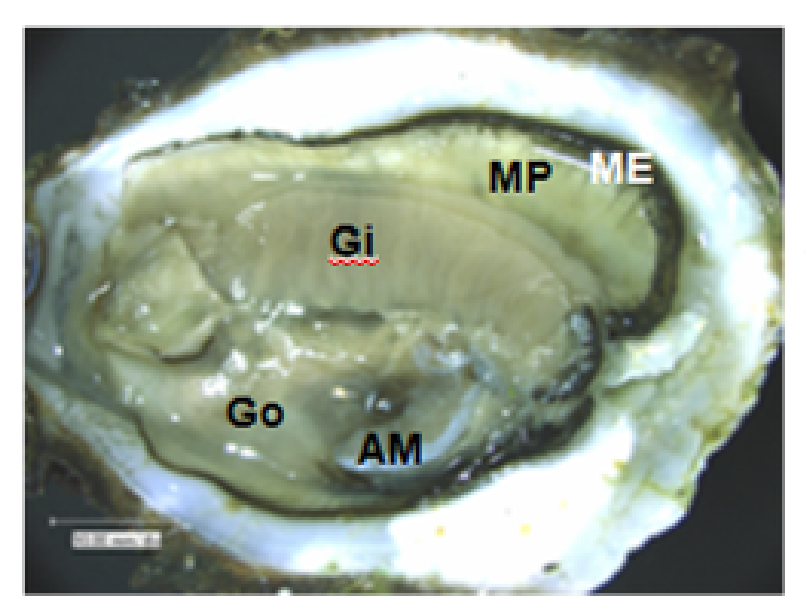

(b)
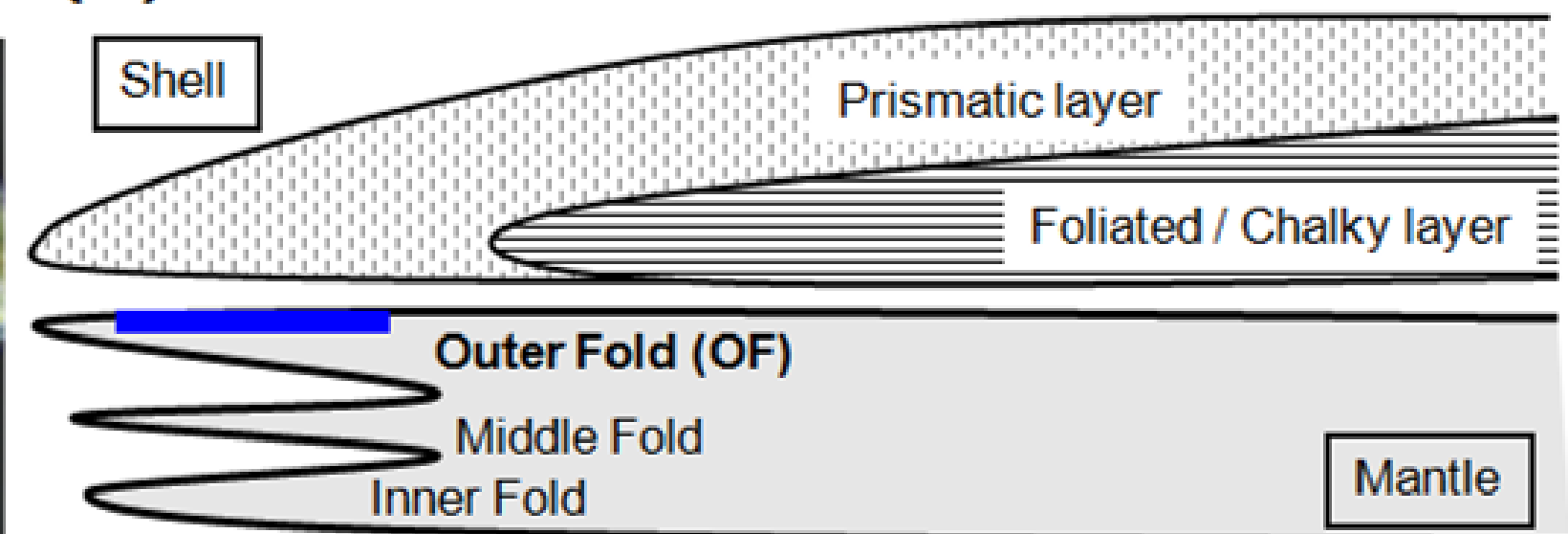

Mantle Edge

Mantle

Mantle Pallial

(c)

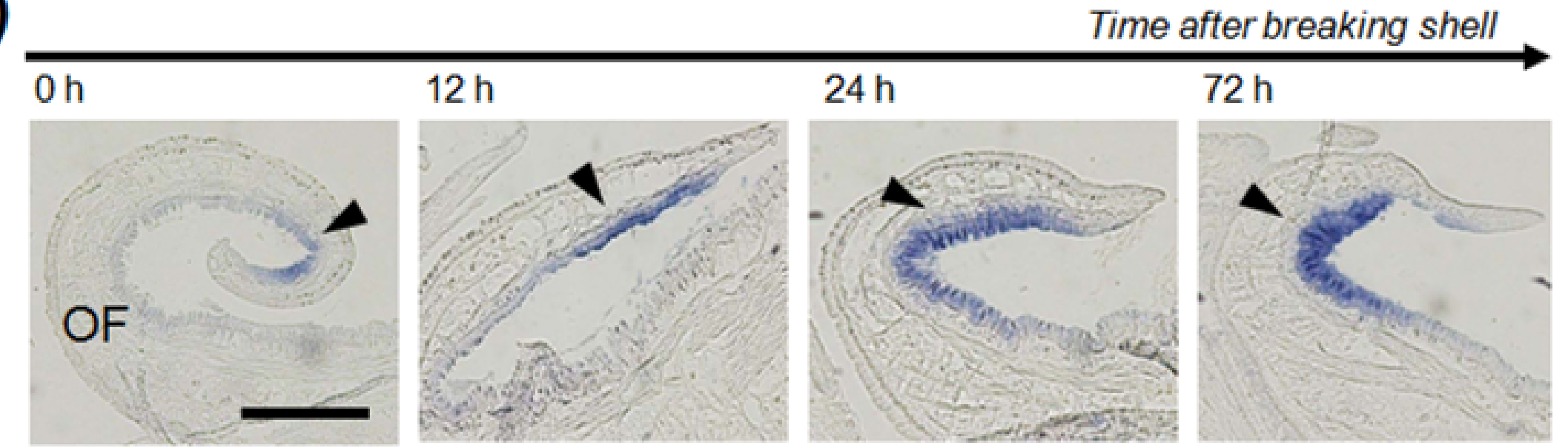

Time after breaking shell

$72 \mathrm{~h}$




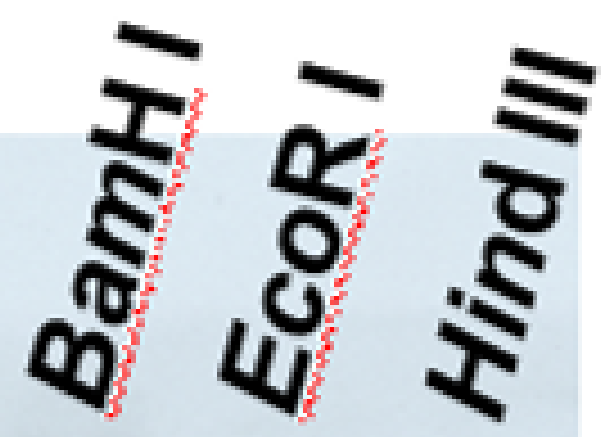

(kbp)

$-10$

$-3.0$

$-1.0$

123 